To Maega $\mid$ Jurnal Pengabdian Masyarakat

Bulan-Tahun, Vol.3, No.2, hal, 111-121

$\operatorname{ISSN}(P): 2622-6332 ; \operatorname{ISSN}(E): 2622-6340$

http://www.ojs.unanda.ac.id/index.php/tomaega

\title{
Strategi Pembelajaran bagi Guru di Lembaga Pendidikan Islam Anak Sholeh Pepelegi, Sidoarjo
}

\author{
Nuril Huda ${ }^{1, a, *}$, Ninik Madiana ${ }^{2, b}$, Imayah $^{3, c}$ \\ $12{ }^{3}$ Pendidikan Bahasa Indonesia, FKIP, Universitas Dr. Soetomo \\ a.b,cemail:nuril.huda@unitomo.ac.id; ninik.mardiana@unitomo.ac.id; \\ imayah@unitomo.ac.id \\ Correspondent email: nuril.huda@unitomo.ac.id
}

Article History:

Received: 14-7-2020; Received in Revised: 19-7-2020; Accepted: 27-7-2020

DOI: http://dx.doi.org/10.35914/tomaega.v3i2.407

\begin{abstract}
Abstrak
Lembaga Pendidikan Islam Anak Sholeh berdiri pada tanggal 18 Desember 2018. Dengan usia yang masih dini ini, LPI Anak Sholeh membutuhkan pihak-pihak lain untuk memperbaiki dan mengembangkan kualitas lembaga. Oleh sebab itu LPI Anak Sholeh bekerja sama dengan tim dosen Unitomo untuk mengadakan penyuluhan dan pelatihan strategi pembelajaran yang menyenangkan bagi guru di sana untuk meningkkatkan sumber daya manusia. Metode pelaksanaan pengabdian ini dimulai dari identifikasi mitra, kesepakatan penentuan objek pelatihan, pelatihan dan pendampingan, dan evaluasi bersama. Hasil yang didapatkan berupa peningkatan kualitas guru dalam mengolah strategi pembelajaran untuk anak prasekolah, baik di ruang kelas maupun di luar kelas. Kesimpulan yang didapat (1) penerapan strategi belajar disesuaikan dengan kebutuhan siswa dan seiring dengan perkembangan zaman, (2) strategi belajar harus mempertibangkan sifat keamanan dan kenyamanan siswa, (3) guru harus terampil menerapkan strategi belajar agar faktor kognitif, psikomotorik, dan afektif siswa berkembang, (4) media pembelajaran yang tepat menunjang strategi belajar mengajar.
\end{abstract}

Kata kunci: strategi belajar, guru, kognitif, psikomotorik, afekstif

\begin{abstract}
The Sholeh Children's Islamic Education Institute (LPI Anak Sholeh) was established on December 18, 2018. With this early age, the LPI Anak Sholeh needs other parties to improve and develop the quality of the institution. Therefore LPI Anak Sholeh worked closely with Unitomo's lecturer team to conduct counseling and training in learning strategies that were fun for the teachers there, to upgrade their human resort development. The method of implementing this service starts from identifying partners, agreeing on the determination of training objects, training and mentoring, and joint evaluation. The results obtained in the form of improving the quality of teachers in processing learning strategies for preschoolers, both in the classroom and outside the classroom. The conclusions obtained (1) the application of learning strategies tailored to the needs of students and along with the times, (2) learning strategies must consider the nature of student safety and comfort, (3) teachers must be skilled in implementing learning strategies so that cognitive, psychomotor and affective factors of students developing, (4) appropriate learning media support teaching and learning strategies.
\end{abstract}

Keywords: learning strategies, teachers, cognitive, psychomotor, affective 


\section{Pendahuluan}

Strategi pembelajaran merupakan penggabungan berbagai macam tindakan untuk mencapai tujuan kegiatan (Nurmadinah, 2015). Dalam hal ini tindakan yang dilakukan tidak sekadar saat pembelajaran, namun strategi pembelajaran memuat sejak rencana hingga bagaimana cara mengevaluasi sebuah pembelajaran. Dalam Undang-undang No. 20 tahun 2003, tentang SISDIKNAS, bagian ke-7, pasal 28 dijelaskan bahwa: (1) Pendidikan Usia Dini diselenggarakan sebelum jenjang pendidikan dasar. (2) Pendidikan Usia Dini dapat diselenggarakan melalui jalur pendidikan formal, nonformal, informal. (3) Pendidikan Usia Dini pada jalur formal berbentuk TK, Raudatul Athfal atau bentuk yang sederajat. (4) Pendidikan pada jalur nonformal berbentuk kelompok bermain (KB), Tempat Penitipan Anak (TPA), bentuk lain yang sederajat. (5) Pendidikan pada jalur pendidikan informal berbentuk pendidikan keluarga yang diselenggarakan oleh lingkungan.

Adapun secara khusus tujuan dari pendidikan usia dini ialah untuk : (a). menyiapkan dengan baik perkembangan kepribadian anak secara menyeluruh/holistik (memenuhi kebutuhan akan perkembangan intelektual dan kognitif, kebutuhan akan kegiatan yang kreatif (psikomorik) dan kebutuhan untuk dapat berdiri sendiri(mandiri), b. memenuhi kebutuhan emosi anak atau kebutuhan akan kasih saying (afektif), (c). Memenuhi kebutuhan akan pergaulan, hubungan sosial, kehidupan berkelompok dan bermasyarakat, (d). Mengajarkan dasar-dasar pengetahuan, (e). Membantu perkembangan fisik dan otak anak, (f). Memenuhi kebutuhan untuk berekspresi dengan bahasa, (g). Menanamkan ajaran-ajaran moral atau agama, kepahlawanan dan kewarganegaraan (Nurmadinah, 2015).

Lembaga Pendidikan Islam Anak Sholeh Pepelegi, Sidoarjo merupakan lembaga pendidikan yang sangat muda dalam kelahirannya. Lembaga ini berdiri sejak 18 Desember 2018, yang diketuai oleh Lukman Fanani. Lembaga pendidikan ini terletak di Jl. Achmad RT.04 RW. 10, Pepelegi, Kecamatan Waru, Sidoarjo. Berdirinya lembaga ini bermula dari keprihatinan warga setempat komplek perumahan di sekitar jalan Achmad yang memiliki anak-anak balita untuk bisa mendapatkan pendidikan formal. Dengan semakin bertambahnya jumlah penduduk di kompleks perumahan tersebut, ditambah dengan keluhan warga yang kesulitan untuk menyekolahkan anak balita mereka, maka muncullah tekad untuk mendirikan lembaga pendidikan untuk jenjang di bawah sekolah dasar.

LPI ini berdiri di luas lahan 458 meter persegi, dengan status pinjam pakai. LPI ini dikepalai oleh Etik Juwaifah, S.Pd dan wakilnya yaitu Alfiyah, S.PdI. Jumlah tenaga pengajar di sana ada Sembilan terdiri dari empat guru dan tiga guru ekstrakulikuler. Sebagai lembaga pendidikan yang baru berdiri, tentunya memerlukan banyak pembinaan dan masukan dari kalangan akademisi yang lain yang sekiranya dapat meningkatkan mutu lembaga tersebut. Untuk saat ini sudah tercatat jumlah rombongan belajar dua rombel yaitu kelas A dan B. tiap kelasnya memiliki rata-rata 30 murid yang berasal dari daerah sekitar LPI. 


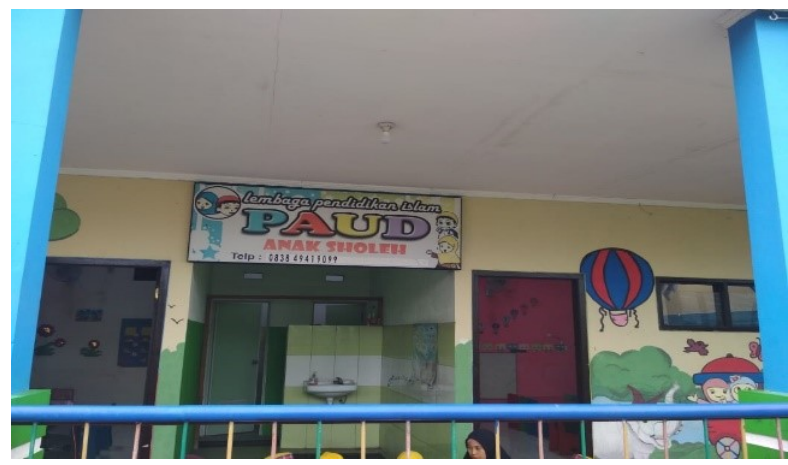

Gambar 1. Salah Satu Sudut Sanitarian LPI Anak Sholeh

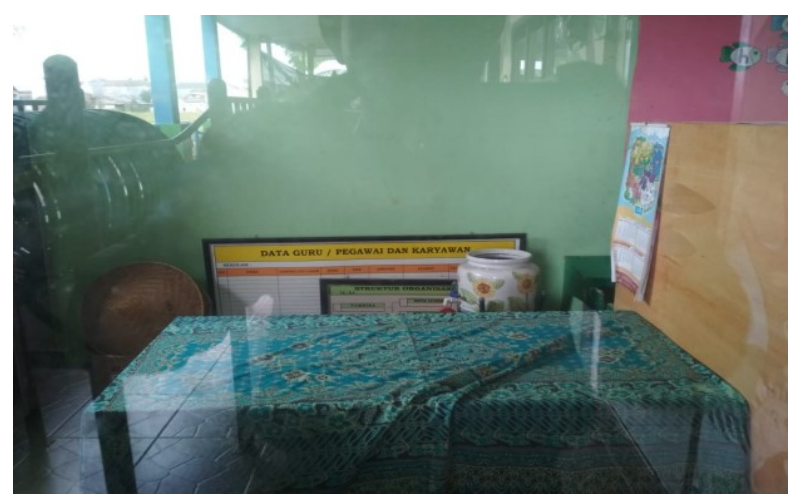

Gambar 2. Sudut Ruang Pertemuan Guru LPI Anak Sholeh

Dalam segi sumber daya manusia (SDM) jumlah guru tetap yag ada di LPI Anak Sholeh berjumlah 4 guru (termasuk kepala sekolah dan wakilnya), lima guru tidak tetap dengan ijazah terakhir SMA, satu tenaga Tata Usaha, dan satu tenaga satpam yang diperbantukan. Untuk fasilitas yang ada terdiri dari dua ruang kelas, dan satu ruang guru. Managemen pemasaran dan managemen keuangan juga sifatnya sederhana. Secara keselutuhan, LPI Anak Sholeh yang usia berdirinya relatif muda masih memerlukan banyak peningkatan mutu. Adapaun hal mendesak adalah bagaimana meningkatkan keterampilan SDM yang dikhususkan pada sosok guru, yang ada di sana mengingat guru adalah motor dari bermutu dan tidaknya sebuag lembaga pendidikan. Guru mempunyai efek langsung yang berimbas pada output siswa.

Dari beberapa item yang telah disebutkan sebelumnya, banyak item yang perlu mendapat perhatian untuk ditingkatkan dan diperlukan perbaikan-perbaikan. Perbaikan-perbaikan tersebut misalnya saja tentang sarana dan prasarana, peningkatan keterampilan guru dalam mengolah kelas atau yang biasa disebut dengan strategi belajar, managemen pemasaran, managemen sekolah, media pembelajaran, dan lain-lain. Sebagai lembaga pendidikan yang baru berdiri dan dari hasil diskusi antara pihak LPI dan tim dosen maka prioritas utama sebagai permasalahan LPI Anak Sholeh adalah penerapan strategi pembelajaran di kelas agar suasana belajar mengajar di kelas cukup menyenangkan bagi siswa. Wawasan 
guru tentang strategi belajar untuk anak prasekolah memang harus dikembangkan, agar nantinya dapat berdampak positif bagi siswa mereka.

Mengingat guru adalah sebagai fasilitator, sumber belajar, dan juga sebagai pengatur jalannya proses belajar mengajar yang menyenangkan di kelas, maka diperlukan peningkatan wawasan dan pelatihan bagi guru-guru yang ada di LPI tentang strategi pembelajaran bagi siswa pra sekolah. Strategi belajar ini mengenai pembelajaran di dalam dan di luar ruangan, serta bagaimana cara menjalankan pengajaran yang menyenangkan bagi siswa namun misi agama juga tersampaikan. Penanaman misi agama sangat diperlukan untuk siswa yang masih dalam masa golden age. Disamping itu peningkatan faktor afektif, kognitif, dan psikomotorik juga bisa menjadi indikator bahwa strategi pembelajaran yang diterapkan dalam kondisi benar.

Mengacu pada butir analisis situasi, dapat diidentifikasi permasalahan pada mitra meliputi beberapa hal berikut ini: (1) Para pengajar masih menggunakan pembelajaran yang konvensional, memerlukan pengembangan wawasan dan pelatihan tentang strategi belajar mengajar yang menyenangkan untuk anak prasekolah. Guru yang mengajar di sana masih perlu meningkatkan keterampilan mereka dalam mengolah kelas pada jenjang prasekolah; (2) Masih minimnya sarana dan prasarana,sehingga membutuhkan kreatifitas untuk dapat memanfaatkan secara maksimal dalam proses belajar-mengajar. Oleh sebab itu strategi pembelajaran dengan memanfaatkan sarana-prasarana yang minim perlu dikembangkan.

Adapun solusi yang bisa diterapkan dalam waktu dekat dan singkat yakni, (1) Memberi jasa pelatihan strategi pembelajaran bagi guru LPI Anak Sholeh oleh tim dosen FKIP Unitomo dan (2) Seluruh guru mampu mewujudkan strategi belajar yang menyenangkan di LPI Anak Shaleh.

\section{Metode}

Berdasarkan uraian sebelumnya, serta hasil diskusi dengan mitra, maka prioritas permasalah yang harus diselesaikan bersama dengan mitra adalah memperkenalkan seluk beluk strategi belajar yang menyenangkan untuk anak prasekolah. Oleh sebab itu perlu adanya pelatihan dan pendampingan tentang strategi pembelajaran untuk mewujudkan suasana belajar mengajar yang menyenangkan di LPI Anak Sholeh Pepelegi, Sidoarjo.

Dalam pelaksanaan program pengabdian masyarakat yangberupa penyuluhan, pelatihan, dan pendampingan dilaksanakan ini memiliki tahapan-tahapan: (1) Identifikasi awal persoalan dengan mitra; (2)Tahap Pelaksanaan; pada tahap ini dilaksanakan pelatihan dan pendampingan dengan metode terbimbing terhadap guru-guru LPI Anak Sholeh Pepelegi Sidoarjo; (3). Tahap Evaluasi Pelaksanaan; pada tahap ini dilaksanakan evaluasi yang dilakukan oleh tim dosen dibantu dengan mitra. Perangkat evaluasi sebelumnya telah disusun oleh tim dosen. Perangkat ini 
digunakan sebagai indikator keberhasilan program pengabdian masyarakat. Adapun prosedur kerja dapat digambarkan sebagai berikut.

Tabel 1. Prosedur pelaksanaan pengabdian di LPI Anak Sholeh

\begin{tabular}{ll}
\hline $\begin{array}{l}\text { Perencanaan } \\
\text { awal }\end{array}$ & $\begin{array}{l}\text { Menetapkan LPI Anak Sholeh Pepelegi Sidoarjo } \\
\text { menjadi mitra dalam program pengabdian masyarakat }\end{array}$ \\
\hline $\begin{array}{l}\text { Identifikasi } \\
\text { dengan mitra }\end{array}$ & $\begin{array}{l}\text { Bersama mitra menetapkan program yang akan } \\
\text { dilaksanakan yaitu: pelatihan strategi pembelajaran } \\
\text { yang menyenangkan di LPI Anak Sholeh Sidoarjo. }\end{array}$ \\
\hline $\begin{array}{l}\text { Pelaksanaan } \\
\text { kegiatan }\end{array}$ & $\begin{array}{l}\text { Tim dosen dibantu mahasiswa dan mitra } \\
\text { melaksanakan metode terbimbing. Pelaksaannya } \\
\text { dimulai dari: Penyuluhan dan penjabaran tentang } \\
\text { strategi pembelajaran, Pelatihan dan bimbingan }\end{array}$ \\
& $\begin{array}{l}\text { strategi pembelajaran secara praktik lapangan, } \\
\text { Pendampingan terhadap guru-guru dalam } \\
\text { mengelola kelas. }\end{array}$ \\
\hline $\begin{array}{l}\text { Evaluasi } \\
\text { Pelaksanaan }\end{array}$ & Tim dosen bersama mitra mengadakan evaluasi \\
bersama. \\
$\begin{array}{l}\text { Hasil } \\
\text { Kegiatan }\end{array}$ & Tim dosen menyusun laporan yang dierahkan ke \\
\hline
\end{tabular}

\section{Hasil dan Pembahasan}

Program Pengabdian Masyarakat ini memiliki target luaran untuk meningkatkan kualitas dan keterampilan guru dalam melaksanakan PBM dengan strategi belajar yang menyenangkan. Dengan kolaborasi yang baik antara tim dosen dan guru-guru yang ada di LPI Anak Sholeh pelatihan dan pendampingan dalam meningkatkan strategi pembelajaran berjalan dengan baik.

Pada pelatihan pertama tim dosen menjabarkan tentang konsep-konsep strategi pembelajaran bagi siswa prasekolah. Karena peralatan yang ada di LPI Anak Sholeh belum mendukung, karena tidak tersedianya LCD proyektor, maka penjabaran yang berlangsung dilakukan dengan metode ceramah tanpa media gambar. Untuk materi tentang strategi belajar dapat dicopy ke pihak kepala sekolah. Dalam materi yang dipaparkan adalah tentang strategi pembelajaran yang mengutamakan pada sifat keamanan dan kenyamanan siswa. Dalam hal ini strategi pembelajaran yang dijabarkan adalah berpusat pada anak yang ditandai dengan: (a) adanya materi yang disesuaikan dengan kebutuhan serta perkembangan anak didik, (b) metode pembelajaran yang menarik dan mengacu pada center of interest melalui pengembangan tematik; (c) media dan sumber belajar yang aman dan dapat memperkaya lingkungan belajar; dan (d) pengelolaan kelas yang bersifat terbukaan, demokratis, saling menghargai sesama, kepedulian lingkungan, (e) dikembangkan unsur lokal yang menjadi tujuan utama LPI Anak Sholeh. Bagaimanapun LPI Anak Sholeh memuat unsur lokal yakni berbasis agama Islam. Maka dakwah tentang 
nilai-nilai agama Islam sedikit demi sedikit ditanamkan ke siswa. Dakwah menurut Huda (2019), adalah segala macam bentuk komunikasi yang di dalamnya menyeru untuk mengamalkan apa-apa yang ada dalam ajaran agama tertentu. Maka muatan lokal LPI Anak Sholeh memuat unsur-unsur agama Islam.

Adapun guru yang mengikuti jalannya pelatihan cukup antusias meskipun mereka usai melaksanakan kegiatan belajar mengajar pada siswa-siswanya. Penjabaran dari strategi pembelajaran mulai dari definisi, jenis-jenis, manfaat, dan segala teknik pembelajaran diuraikan di sini. Dalam sesi ini juga dijabarkan tentang bagaimana kondisi fisik, psikologis, kognitif siswa yang notabene masih dalam masa golden age. Pemaparan materi-materi ini merujuk dari beberapa referensi yakni Gulo (2008), Desmita (2012), Djamarah (2008), Hamalik (2009), Majid (2010), Hamdayama (2014), dan Sunarto (2006).

Dari segi perkembangan psikologi, maka siswa LPI Anak Sholeh berada dalam masa golden age, yang terbuka pada segala masukan. Oleh karenanya dalam kesempatan penyuluhan pertama dijabarkan tentang psikologi perkembangan peserta didik beserta contoh-contoh konkrit bagaimana guru dapat memahami psikologi anak prasekolah.

Dalam pelatihan pertama ini pula, tim dosen juga menjabarkan bagaimana cara membuat Rencana Pembelajaran Persemester (RPP) dan Satuan Acuan Pembelajaran (SAP) bagi guru prasekolah. RPP ini tentu saja sangat berguna sebagai panduan bagi guru dalam mengolah kelas. Dalam RPP dan SAP termuat apa saja tujuan pembelajaran, metode pembelajaran yang dipakai, rencana guru dan juga siswa dalam skenario pembelajarannya, hingga sampai pada evaluasi sederhana dalam menilai keberhasilan proses belajar mengajar di kelas. Jabaran selanjutnya yakni mengenai jenis-jenis strategi aktif terpadu bagi Anak Usia dini. Penjabaran ini menyangkut tentang: (1) Strategi BCCT atau (Beyond Centre and Circle Time); (2) Strategi Lempar Bola; (2) Strategi Brainstorming Simpel; (3) Strategi Pengulangan Cerita Aktif; (4) Strategi Rekam Jejak; (5) Pembelajaran berbasis Masalah (Hasanah, 2018)

Pada pelatihan kedua mulai ada penjabaran dan praktik langsung dalam berstrategi pembelajran yang baik. Dalam hal ini tim dosen dan guru-guru mengatur variasi tempat duduk siswa. Variasi tempat duduk, berguna untuk dinamisasi faktor kognisi dan psikomotorik siswa. Variasi ini bisa disusun misalnya berjajar, melingkar membentuk grup kecil, atau dengan membuat blok-blok kecil yang terdiri 4 siswa per blok. Menghias dinding dengan hasil pekerjaan siswa juga bagian dari strategi belajar yang menarik siswa untuk betah belajar di dalam kelas. Variasi tempat duduk ini kami sarankan berubah per pekan, agar siswa belajar secara langsung tentang perlunya beradaptasi. Keterampilan beradaptasi sangat perlu disiapkan pada masa golden age siswa. Seni mengelola fisik atau tampilan interior kelas merupakan pula bagian dari strategi pembelajaran, agar dapat mengembangkan kapasitas faktor afektif, psikomotorik, dan kognitif siswa. Dalam hal ini segi keamanan dan kenyamanan siswa juga diperhatikan. Pengenalan warna 
pada sisi interior kelas juga dipaparkan dalam tatap muka pelatihan dan pendampingan guru oleh tim dosen Universitas Dr. Soetomo Surabaya.

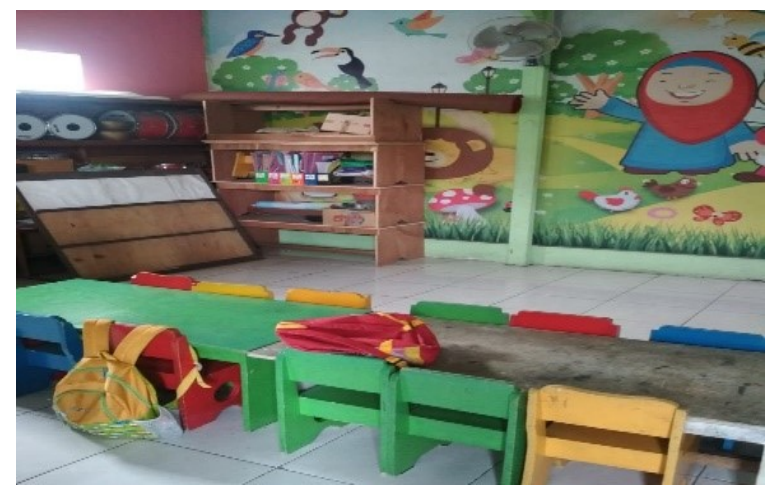

Gambar 3. Pengaturan Posisi Tempat Duduk Siswa yang Berjajar

Pada pelatihan ketiga, tentang strategi belajar di luar ruangan. Belajar di luar ruang kelas, tidak harus saat olah raga, bisa tentang tema lain. Dalam hal ini bisa guru praktik langsung bersama siswa- siswa. Meskipun lahan agak minim, masih bisa dimanfaatkan untuk pembelajaran di luar ruangan. Belajar di luar ruangan selain untuk memancing impuls siswa agar lebih kreatif, juga menghindari kebosanan. Diperlukan peralatan alas lantai agar jika siswa duduk di lantai tidak merasa kedinginan.

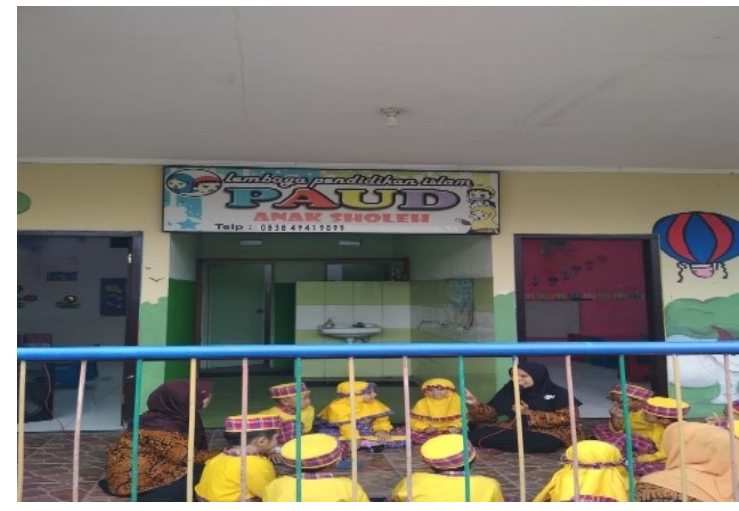

Gambar 4. Suasana Pembelajaran di Luar Ruang Kelas.

Dari hasil evaluasi, yang dilaksanakan antara tim dosen dan mitra, ada peningkatan keterampilan guru dalam proses pelaksanaan PTK. Hal ini tampak dalam bagan berikut.

Tabel 2. Perbedaan Sebelum dan Sesudah Dilaksanakan Pendampingan PPM

\begin{tabular}{llll}
\hline No & Aspek & Sebelum & Sesudah \\
\hline $\mathbf{1}$ & Konsep strategi & Belum ada & Sudah mampu merumuskan konsep \\
& $\begin{array}{l}\text { belajar bagi anak } \\
\text { prasekolah }\end{array}$ & bayangan & $\begin{array}{l}\text { strategi belajar untuk anak } \\
\text { prasekolah. }\end{array}$ \\
\hline
\end{tabular}




\begin{tabular}{|c|c|c|c|}
\hline 2 & $\begin{array}{l}\text { Strategi } \\
\text { pembelajaran di } \\
\text { dalam dan di luar } \\
\text { kelas }\end{array}$ & $\begin{array}{l}\text { Pembelajaran } \\
\text { olah raga }\end{array}$ & $\begin{array}{l}\text { Pembelajaran yang meluas, tidak } \\
\text { sekedar olah raga. }\end{array}$ \\
\hline 3 & $\begin{array}{l}\text { Perumusan solusi } \\
\text { strategi } \\
\text { pembelajaran } \\
\text { (missal: berhitung } \\
\text { dan mengenal } \\
\text { angka 1-5) }\end{array}$ & $\begin{array}{l}\text { Belum } \\
\text { mampu } \\
\text { memberi } \\
\text { solusi }\end{array}$ & $\begin{array}{l}\text { Mampu merumuskan dan } \\
\text { memberikan solusi yang dihadapi di } \\
\text { kelas. (dengan cara bermain dan } \\
\text { berimajinasi) }\end{array}$ \\
\hline 4 & $\begin{array}{l}\text { Melaksanakan } \\
\text { strategi belajar } \\
\text { yang sesuai }\end{array}$ & $\begin{array}{l}\text { Sudah } \\
\text { dilakukan, } \\
\text { namun } \\
\text { kurang } \\
\text { bervariasi. }\end{array}$ & $\begin{array}{l}\text { Sudah dilakukan dan lebih } \\
\text { bervariasi. Pengaturan tempat } \\
\text { duduk, hiasan interior kelas yang } \\
\text { berfungsi positif, menyusun RPP } \\
\text { dan SAP. }\end{array}$ \\
\hline 5 & $\begin{array}{l}\text { Hasil langsung ke } \\
\text { siswa }\end{array}$ & $\begin{array}{l}\text { Siswa tampak } \\
\text { biasa saja }\end{array}$ & $\begin{array}{l}\text { Siswa lebih antusias belajar. Siswa } \\
\text { merasa selalu ada yang baru dalam } \\
\text { mengikuti pembelajaran. }\end{array}$ \\
\hline
\end{tabular}

Dengan adanya pelatihan dan pendampingan guru-guru di LPI Anak Sholeh dapat dihasilkan peningkatan-peningkatan keterampilan dalam hal strategi belajar mengajar. Hal ini tampak pada keterampilan mereka daam menyusun RPP dan SAP, menata interior kelas dan dampak-dampak dari penataan interior kelas, melakukan variasi pembelajaran di dalam dan di luar kelas. Dari segala hasil yang didapat yang terpenting adalah berdampak ke siswa. Para siswa akhirnya lebih antusias dalam belajar. Walau beberapa siswa tampak agak bingung terhadap perubahan, tetapi bisa mengikuti perubahan kecil yang dilakukan oleh guru-guru mereka. Sebagaimana yang diungkapkan oleh Putri (2020), bahwa peningkatan kompetensi mengajar merupakan hal yang penting dan selalu dibutuhkan bagi guru agar berdampak positif bagi siswa-siswanya.

Adapun luaran yang sudah berhasil dicapai dalam rangkaian kegiatan keseluruhan pengabdian program DIPA terlihat pada tabel berikut:

Tabel 3. Persentase Capaian

\begin{tabular}{lll}
\hline No & LUARAN & CAPAIAN \\
\hline 1 & Jasa Pelatihan berupa penyuluhan dan pendampingan & $100 \%$ \\
\hline 2 & Produk: Hasil kerja guru dalam PBM & $75 \%$ \\
\hline 3 & Penulisan artikel ilmiah & $100 \%$ \\
\hline 4 & Peningkatan keterampilan guru (SDM) & $75 \%$ \\
\hline
\end{tabular}

Dalam hal pelaksanaan yang berupa jasa pelatihan dan pendampingan untuk guru di TPI Anak Sholeh serta presentasi hasil akhir pengabdian berlangsung dengan baik dan tuntas $100 \%$. Untuk hasil kerja guru dalam bentuk penerapan strategi belajar yang bervariasi, dua guru tetap telah melaksanakan, sementara dua guru belum melaksanakan karena terkendala situasi dan kondisi sekolah. Itulah 
sebabnya hasil yang didapat dari pelatihan dan pendampingan saat ini untuk LPI Anak Sholeh dapat dinilai 75\% keberhasilannya. Hal ini karena memang ada kondisi guru yang kesehatannya agak kurang sehat, sehingga tidak maksimal dalam melaksanakan berbagai kegiatan pelatihan dan pendampingan dari tim dosen Unitomo. Kendala berikutnya adalah latar belakang guru tetap yang ada di sana 25\% berlatar pendidikan, dan selebihnya lulusan SMA dan di luar jalur pendidikan.

Hal ini menyebabkan tim dosen memulai lebih awal dan dengan penggunaan bahasa yang umum, agar dimengerti para guru yang tidak berlatar pendidikan. Istilah-istilah pendidikan dan bagaimana pengolahan belajar mengajar kami sajikan dengan pola sederhana dan bahasa yang sederhana. Keadaan ini bukan hambatan bagi tim dosen yang memberikan pelatihan, justru ini adalah tantangan untuk membuka wawasan bagi para pendidik yang bukan dari kalangan pendidikan untuk lebih faham dalam persoalan mengolah kelas. Tidak hanya sekedar itu, masalah psikologi peserta didik, perkembangan kognitif siswa, diperkenalkan pada mereka. Dengan bahasa yang sederhana, suasana yang rileks, penuh dengan kekeluargaan dan kehangatan membuat para guru dan tim dosen dapat menjalin suasana pelatihan yang baik.

Beberapa kendala yang menjadi catatan dari tim dosen pengabdian adalah mengenai kesepakatan waktu. Dua kali tercatat antara tim dosen dan pihak LPI Anak Sholeh tidak menemui titik kemufakatan. Hal ini disebabkan masing-masing pihak memiliki kesibukan prioritas yang berbeda, sehingga dua kali mengalami kesulitan. Pada akhirnya tiga kali tatap muka dapat dijalankan dengan baik. Pertemuan tersebut juga mempertimbangkan tidak merugikan waktu bagi peserta didik yang belajar.

Untuk luaran penulisan laporan pengabdian sebagai artikel dan juga sebagai Laporan Akhir Kegiatan sudah diselesaikan 100\%. Dalam peningkatan keterampilan guru dalam melaksanakan strategi pembelajaran sesuai dengan evaluasi yang kami lakukan bersama, guru-guru yang ada di LPI Anak Sholeh sudah mencukupi kriteri bagus. Dua guru tetap telah memenuhi kriteria bagus, satu dalam kriteria cukup, dan seorang guru kami nyatakan cukup bagus, hanya karena kendala kesehatan saja sehingga ada kendala pada guru tersebut.

\section{Kesimpulan}

Dari rangkaian kegiatan program pengabdian masyarakat ini diperoleh simpulan bahwa (1) pengembangan strategi pembelajaran sangat diperlukan dalam proses belajar mengajar dan harus mengikuti perkembangan zaman serta disesuaikan dengan tingkat kebutuhan siswa, (2) perlunya strategi belajar di luar dan di dalam kelas yang memenuhi keamanan dan kenyamanan dalam belajar, (3) sebagai guru harus terampil menerapkan strategi belajar yang tepat agar dapat mengembangkan faktor kognitif, psikomotorik, dan afektif untuk siswanya (4) diperlukan pengembangan dalam segi lain (misal: pengembangan media pembelajaran) untuk inovasi dan kreasi pembelajaran yang menyenangkan dan tidak monoton. Hal ini berguna bagi siswa sebagai pelaku pembelajar. 
Adapun saran yang diberikan yaitu diperlukan kerjasama yang baik antarinstitusi agar satu dengan yang lain memberi kontribusi yang saling menguntungkan dan berhasil dengan nilai yang positif. Berawal dari penerapan strategi belajar yang baik, akan tercipta suasana belajar mengajar yang baik pula, yang hasil akhirnya adalah peningkatan kualitas pada siswa baik dari segi psikomotorik, kognitif, dan afektif. Untuk selanjutnya diperlukan usaha pengadaan latihan tentang media pembelajaran, pengembangan managemen sekolah, pengembangan tema lokal sekolah, dan lain-lain yang kesemuanya berguna bagi lembaga, guru, dan siswa, serta stake holder LPI Anak Sholeh.

\section{Ucapan Terimakasih}

Ucapan terima kasih, ditujukan kepada; (1) Rektor Universitas Dr. Soetomo Surabaya, Bapak Dr. Bachrul Amiq, S.H., M.H., yang telah memberikan dukungan penuh pada para dosen dalam melaksanakan Tri Dharma Perguruan Tinggi, dengan kebijakan-kebijakannya; (2) Dekan Fakultas Keguruan dan Ilmu Pendidikan, Dr. Hetty Purnamasari, M.Pd., yang telah memberikan dukungan dan stimulus positif untuk para dosen yang melaksanakan Tri Dharma Perguruan Tinggi; (3) Rekanrekan dosen yang selalu saling mendukung dan mengingatkan dalam segi yang positif; (4) Pimpinan LPI Anak Sholeh dan Kepala Sekolah, yaitu Bapak Lukman Fanani dan Ibu Evi Juwaifah, yang telah mempercayakan kerjasamanya dengan tim dosen dari FKIP, Universitas Dr. Soetomo Surabaya serta memberi dukungan baik moril maupun materil serta para guru-guru yang ada di LPI Anak Sholeh, yang dengan semangat dan antusias mengikuti setiap sesi pendampingan; (6) Mahasiswa yang turut membantu kami dalam menyiapkan properti yang dibutuhkan oleh im dosen FKIP Universitas Dr. Soetomo Surabaya.

\section{Daftar Pustaka}

Desmita. (2012). Psikologi Perkembangan Siswa. Bandung: Rosda Karya

Djamarah, S.B. 2008. Psikologi Pendidikan. Jakarta: Rineka Cipta

Gulo, W. 2008. Strategi Belajar Mengajar. Jakarta: Grasindo.

Hamalik, O. (2009). Proses Belajar Mengajar. Jakarta: Bumi Aksara.

Majid, A. (2010). Strategi Pembelajaran. Bandung: Rosda Karya.

Hamdayama, J. (2014). Model dan Metode Pembelajaran Kreatif dan Berkarakter. Bogor: Ghalia Indonesia.

Hasanah, U. (2018). "Strategi Pembelajaran Aktif untuk Anak Usia Dini”. Jurnal Insania, 23(2), 204-222, IAIN Purwokerto.

Huda, Nuril; Sumartono; dan Ninik Mardiana. 2019. "Persepsi dan Aktivitas Pascapersepsi Mahasiswa FKIP Unitomo terhadap Dakwah di Media Sosial'. Jurnal Civic Culture, 3(2), 266-274, Bangkalan: STKIP PGRI.

Nurmadinah. (2015). Strategi Pembelajaran Anak Usia Dini. Jurnal Al-Afkar, III(1), Bandung:UIN Sunan Gunung Jati. 
[ 121 ] Nuril Huda, dkk / To Maega : Jurnal Pengabdian Masyarakat, Vol.3; No.2; Agustus, 2020

Putri, E. A., Hariyanto, E., Sunaryo, T., \& Hisyam, C. J. (2020). Pelatihan Peningkatan Kompetensi Mengajar Bagi Petugas Lembaga Pembinaan Khusus Anak (LPKA) Tangerang, Banten. To Maega | Jurnal Pengabdian Masyarakat, 3(1), 36-46.

Sunarto dan Hartono. (2006). Perkembangan Peserta Didik. Jakarta: PT. Asdi Mahastya 